\title{
Artificial nutrition and hydration in the patient with advanced dementia: is withholding treatment compatible with traditional Judaism?
}

Muriel R Gillick Hebrew Rehabilitation Center for Aged, Boston, Massachusetts, USA

\begin{abstract}
Several religious traditions are widely believed to advocate the use of life-sustaining treatment in all circumstances. Hence, many believe that these faiths would require the use of a feeding tube in patients with advanced dementia who have lost interest in or the capacity to swallow food. This article explores whether one such tradition - halachic fudaism - in fact demands the use of artificial nutrition and hydration in this setting. Traditional (halachic) arguments have been advanced holding that treatment can be withheld in persons who are dying, in individuals whose condition causes great suffering, or in the event that the treatment would produce suffering. Individuals with advanced dementia can be considered to be dying, often suffer as a result of their dementia, and are likely to suffer from the use of a feeding tube. Given these observations and the absence of a compelling case for distinguishing between tube feeding and other forms of medical treatment, traditional fudaism appears compatible with withholding artificial nutrition for individuals with advanced dementia.

(Fournal of Medical Ethics 2001;27:12-15)
\end{abstract}

Keywords: Nutrition; hydration; Judaism; religion; dementia

Dementia, a condition afflicting over 30 million people worldwide, is a fatal neurological disorder involving progressive loss of memory, judgment, language, and other aspects of cognition, and resulting in death within eight to ten years of the time of diagnosis. In its most advanced stage, the affected individual loses the capacity to communicate or to help with personal care and suffers from severe memory loss. ${ }^{1}$ Deciding what constitutes appropriate medical treatment for individuals with advanced dementia has engendered considerable ethical debate. ${ }^{2}$ Particularly problematic is the question of whether artificial nutrition and hydration should be instituted in those people suffering from advanced dementia who develop difficulty eating and drinking. ${ }^{3}$

Several distinct factors conspire to create nutritional problems among demented patients. Individuals with severe dementia often lose interest in food and drink, concomitant with a generalised indifference to their environment. In addition, they typically develop difficulty with the complex, coordinated process of swallowing. Finally, elderly people in general have an impaired capacity to experience thirst and those with dementia are no exception.

Throughout human history, and in most countries of the world today, a person with severe dementia and trouble eating will die in a matter of weeks or at most months. Contemporary technology, however, offers the possibility of extending the lives of those with advanced dementia through the surgical insertion of a gastrostomy tube, a tube placed through the skin and the abdominal wall into the stomach. Once this procedure has been performed, nutrients and fluid can be administered through the tube.

In the United States, 120,000 elderly people undergo gastrostomy placement each year. ${ }^{4}$ Some of these people have had strokes or suffer from cancers of the mouth or oesophagus. A significant fraction - in one study 29\% - have dementia. ${ }^{5}$ Many ethicists and geriatricians have argued that the inability to eat is part of the dying process in demented persons and that the appropriate response should not be to try to postpone impending death with technology. ${ }^{6}$ Should physicians recommend feeding tubes for demented patients? Should families request or accept gastrostomy tube placement?

The conventional answer to these questions, consistent with contemporary Western secular biomedical ethics, is to allow the patient to decide or, since the demented patient by definition is unable to understand the issues, the patient's surrogate. The surrogate, in turn, is supposed to decide based on what the patient would want in those circumstances. Given that few individuals have specifically addressed the issue of whether they would wish their life sustained by artificial nutrition and hydration if they developed dementia, the surrogate is asked to decide by inferring the patient's wishes from his or her values. Since drawing such inferences is at best difficult, most family members or formally designated proxies ultimately make a decision by weighing the benefits of the intervention against its burdens.

The majority of families, when presented with the pros and cons of tube feedings, do not favour 
treatment that aims exclusively to prolong life, given what they view as the poor quality of the demented person's life. ${ }^{7}$ Some families, however, reject arguments based on quality of life and feel obligated to accept any intervention that has a chance of prolonging life, for however brief a period of time. It is widely assumed, for instance, that "pro-life" religions require the use of feeding tubes in advanced dementia. Does an obligation to use feeding tubes in fact arise from these traditions, or can the tradition itself offer a very different answer to this dilemma? This paper will explore the approach to artificial nutrition and hydration in the demented individual consistent with halachic Judaism, a tradition associated with advocating lifesustaining treatment in all circumstances.

The principle of the sanctity of human life is at the centre of traditional Jewish thinking. ${ }^{8}$ People are to be valued because they are human, and not merely in accordance with their talents, wealth, or contributions to society. Indeed, the duty to preserve our lives (pekuach nefesh) and the corollary obligation of the physician to preserve the lives of his or her patients, take precedence over almost al other commandments that a religious Jew is supposed to obey. The principal reason for this injunction is that human beings are made in God's image. Honouring humanity by preserving life is a means of honouring God. In addition, life is viewed as a gift from God that is held in trust by the individual. One is "duty bound to care for one's life and health". ${ }^{9}$ But does this conception of the sanctity of life imply that we should attempt to sustain those with advanced dementia by the use of artificial hydration and nutrition? One of the most widely quoted references on Jewish medical ethics claims that it does. ${ }^{10}$ This contention is based on the following assertions and arguments that are widely held to follow directly from Jewish law (halacha) life-sustaining treatment must always be given to patients unless they are terminally ill. Since people with advanced dementia are not dying, they should receive life-sustaining treatment. The only exception to this principle is that treatment can be withheld if it causes or prolongs suffering. Since dementia is not a painful condition, dementia does not constitute an exception. Moreover, even if dementia were a terminal illness or even if it did cause suffering, artificial nutrition and hydration could not be withheld because they are distinct from medical care and can under no circumstances be denied.

To ascertain whether traditional Judaism in fact requires that people with advanced dementia and eating difficulties be fed via a feeding tube, we must address three separate questions from within the halachic tradition: are patients with advanced dementia dying? Does either dementia itself or the use of feeding tubes in the setting of dementia cause suffering? Is artificial nutrition and hydration substantively different from medical treatment?

\section{Is a person with advanced dementia "dying"?}

The question of whether an individual with advanced dementia is dying is critically important because there is an extensive literature suggesting that if a person is a goses (a moribund person), there is no obligation to try to prolong his or her life. On the contrary, some would argue, it is important to remove any impediments to the person's dying. By way of example, rabbinic commentators frequently cite the Talmudic story of Rabbi Judah the Prince (Ketubot 104a), who was dying a painful death and whose followers tried to prevent his death through prayer. His handmaid, observing his suffering, dropped some dishes to distract the praying followers. During the instant that they ceased praying, Rabbi Judah's soul departed. ${ }^{11}$ The implication is that a person whose death is imminent should be allowed to die. Some individuals with advanced dementia are clearly moribund: they cannot even swallow their own saliva, and will undoubtedly die in a matter of days from aspiration of their secretions, whether or not a feeding tube is inserted. At this extreme stage, the sufferer from Alzheimer's fits the talmudic description of a goses as a patient whose death is imminent because "he has lost control of bodily functions as manifested by his inability to bring up secretions from his chest". ${ }^{12}$

While most patients with advanced dementia cannot be regarded as goses, they can be regarded as treifah (being in a condition for which there is no cure and from which they will "surely die".) Traditional texts distinguish between treatments that can effect long term cure and those that can merely extend life for a short time, usually defined as less than one year. Some commentators indicate that it is permissible to remove any impediment to death, even if a person is not a goses (expected to die in a matter of days), but is merely a treifah. ${ }^{8}$ The distinction between withholding life-prolonging measures from someone who is expected to die in days and from someone who is expected to die within a year is probably anachronistic: it was made because, in previous eras, physicians were unable reliably to diagnose the state of treifah. Only a person who is a goses was certain to be dying. More sophisticated prognostic capacities, which enable physicians to predict with reasonable accuracy that death will occur within a year, allow individuals with a slightly less dire prognosis to be viewed, none the less, as dying. ${ }^{11}$

At the present time, dementia is a progressive, irreversible condition that inevitably results in death. Studies of elderly persons with advanced dementia and impaired eating or swallowing show that the median survival is approximately six months, ${ }^{5}$ and interestingly, the survival time is the same for those with a gastrostomy tube and those who do not have a feeding tube. ${ }^{13}$ Thus, an individual with advanced dementia who has reached the stage in which he or she cannot eat can be regarded as dying. From this perspective, withholding possibly life-sustaining medical treat- 
14 Artificial nutrition and hydration in the patient with advanced dementia: is withholding treatment compatible with traditional Fudaism?

ment from those with severe dementia is consistent with halacha.

\section{Are persons with advanced dementia suffering?}

Many traditional Jewish commentators acknowledge that a person who is terminally ill, whether he is a goses or treifah, is not obligated to undergo lifeprolonging measures that produce or prolong suffering: "If the underlying illness is very painful, it is not obligatory to administer medication that will only prolong the life of suffering without any hope of cure". Assuming that feeding tubes can in fact prolong life, which is far from clear, then whether artificial nutrition prolongs suffering depends on whether dementia is a painful condition. ${ }^{14}$ Dementia is not inherently a physically painful condition, though it is often associated with the development of painful problems. The immobility of the person with advanced dementia, for example, may lead to the development of a pressure ulcer, a painful skin condition. In addition, patients with advanced dementia develop contractures (the inability to straighten their limbs) as well as recurrent episodes of pneumonia.

Patients with advanced dementia do not have the cognitive capacity to experience existential suffering - they are unaware of their condition, they do not know or understand that they were once able to think and to reason, and therefore they cannot be distressed by their loss. However, the corollary of this profound lack of understanding is that discomforts such as having one's blood drawn or other tests performed, discomforts that may be welltolerated by a cognitively intact person who understands their justification, are often frightening to someone who cannot comprehend what is being done. From this perspective, advanced dementia is inextricably bound up with suffering. Reasoning based on halacha implies that life-sustaining treatment may be inappropriate in cases of severe dementia because it prolongs suffering.

Feeding tubes have the potential to produce suffering, quite apart from whether the person with advanced dementia is suffering from his underlying disease. Patients with gastrostomy tubes commonly are physically restrained to prevent them from pulling out the tube. ${ }^{15}$ Typically this entails tying the hands to the side of the bed or chair. Despite the difficulties in assessing the emotional state of a person with advanced dementia, most observers believe that restraints are demeaning and distressing to all patients, regardless of their cognitive status. ${ }^{16}$ Halachic authorities have argued that artificial nutrition should not be forced on someone who resists: "Certainly one should never compel a sane adult to eat by employing physical force". ${ }^{17}$ The applicability of this assertion to the case of an individual with advanced dementia is unclear. Nevertheless, tube feeding, at least in those instances in which the recipient repeatedly attempts to remove the tube, may cause suffering. According to traditional arguments, life-sustaining treatment could be withheld under such circumstances; indeed, the pre-eminent halachic authority, Rav
Moshe Feinstein, has indicated that in patients who can live for only several weeks or months, the "key concern is their quality of life". ${ }^{18}$

\section{Is artificial hydration and nutrition a special case?}

Most contemporary traditional Jewish commentators assert that food and fluids must always be provided, even to a severely demented person who has lost the capacity to swallow. Every patient must be fed because "food is a requirement of nature, for all people and even for animals, in order to sustain life" ". ${ }^{19}$ This is contrasted with medicine, which is not "natural" and can be withheld. Thus, even if life-sustaining medical treatment can be withheld from demented individuals, either because they are dying or because they are suffering, nutrition may not be withheld.

But oxygen is just as "natural" and "necessary" as nutrition to sustain human life, and the rabbinic interpreters of Jewish law accept withholding of a respirator to provide oxygen on the grounds that it is an "extraordinary measure". ${ }^{12}$ Clearly, it would be wrong to withhold food and drink from someone who was able to take food by mouth, just as it would be wrong to put a person in a room with no oxygen. But "withholding" nutrition is an inaccurate description of what takes place when a feeding tube is not inserted into a person with advanced dementia. That person has lost interest in food and will not swallow, or has lost the capacity to eat, as part of his progressive, irreversible dementing illness. When he or she is offered food, the person pushes it away, or takes only a tiny amount, or chokes on it. Compelling him or her to take in nutrition artificially-via a surgically placed tube - is no different from compelling him or her to take oxygen in through a respirator if he or she cannot breathe independently. Thus, while it may be true that "food is not at all comparable to medication since food is a natural substance which all living creatures require to maintain life" ${ }^{17}$ it is not true that "artificial nutrition" is synonymous with "food". Some halachic authorities have in fact taken the position that artificial nutrition is a form of medical therapy.

A second reason why many traditional Jewish commentators believe artificial nutrition and hydration constitute a special case is that they are concerned with the comfort of the patient: they assume that food and fluids are necessary for comfort. Current data indicate that individuals who have lost either the capacity or the will to eat, typically from metastatic cancer, and who are lucid enough to describe the sensations they experience, uniformly deny hunger or thirst. ${ }^{20}$ By extrapolation, the patient with advanced dementia who can no longer eat does not, as best as can be determined, experience discomfort from his under-nourished state.

A third reason why traditional Jewish thinkers treat artificial nutrition and hydration as a special case is that they wish to show respect to the still living body of the person with advanced dementia. The belief that the person with endstage dementia 
should be nourished rests on an association between "feeding" and "caring". What is at issue here is how we define what we mean by "caring". There is little that is caring or nurturing in surgically invading the stomach of an uncomprehending person and subsequently utilising a mechanical pump to instill a chemical solution into the tube. ${ }^{21}$ Clearly, finding means to demonstrate caring and respect are essential: the individual with advanced dementia must be kept from experiencing pain or cold or callousness. Tube feeding does not fall into the category of such essential activities. The Jewish arguments for distinguishing between artificial nutrition and hydration and medical treatment are not substantively different from those previously advanced by secular bioethicists. Just as the prevailing view in secular circles is that artificial nutrition is a form of medical therapy, ${ }^{22}$ so too it should be considered treatment within a traditional Jewish framework.

Once we have considered these three questionsare those with severe dementia dying, do the severely demented suffer, and is artificial nutrition and hydration separate from medical treatment, we can arrive at some conclusions about the approach to feeding that is consistent with a tradition such as halachic Judaism that places a strong emphasis on the sanctity of life. Those with advanced dementia are dying: they have an incurable condition with a life expectancy that is typically one year or less. They are suffering, since their dementia often results in their finding even routine activities such as being dressed, bathed, or moved frightening and uncomfortable. And while food and drink should never be withheld from those with eating or swallowing problems and dementia who are hungry or thirsty, individuals with advanced dementia who stop eating do not experience these symptoms. Nutrition and hydration administered via a feeding tube are no more natural and necessary than is oxygen administered via a ventilator.

The focus on the sanctity of life that is central to traditional Judaism implies that those with severe dementia should be treated with respect and care. This includes being kept warm, being offered food and drink, being kept clothed, and being treated with gentleness and kindness. Most, though not all, rabbinic commentators have maintained that the tradition necessitates the use of artificial nutrition and hydration. My analysis indicates that such a conclusion is based on a misunderstanding about the nature of artificial hydration and nutrition, a lack of awareness of the nature of Alzheimer's disease, and a failure to appreciate the consequences of withholding tube feeding. Palliation of the person with advanced dementia is consistent with traditional Judaism.

\section{Acknowledgement}

Many thanks to Dr Amitai Oberman for identifying crucial sources, making insightful comments on the manuscript, and serving as a guide to the perplexed.
Muriel R Gillick, MD, is Director of Medical Education at the Hebrew Rehabilitation Center for Aged, and Director of the Harvard Geriatrics Fellowship Program. She sees patients both at the Hebrew Rehabilitation Center for Aged and at Beth Israel Deaconess Medical Centre. Both are in Boston, Massachusetts, USA.

\section{References}

1 Hughes C, Berg L, Danziger W, Coben L, Martin R. A new clinical scale for the staging of dementia. British fournal of Psychiatry 1982;140:556-72.

2 Post S. The moral challenge of Alzheimer disease. Baltimore, MD: Johns Hopkins University Press, 1995.

3 Luchins D, Hanrahan P. What is appropriate health care for end-stage dementia? Fournal of the American Geriatrics Society 1990;41: 5-30.

4 Grant M, Rudberg M, Brody J. Gastrostomy placement and mortality among hospitalized Medicare beneficiaries. Fournal of the American Medical Association 1998;279:1973-6.

5 Rabeneck L, Wray N, Peterson N. Long-term outcomes of patients receiving percutaneous endoscopic gastrostomy tubes. Fournal of General Internal Medicine 1996;11:287-93.

6 Lo B, Dornbrand L. Guiding the hand that feeds. Caring for the demented elderly. New England Fournal of Medicine 1984;311:402-4.

7 Cogen E, Patterson B, Chavin S, Cogen J, Landsberg L, Posner J. Surrogate decision-maker preferences for medical care of severely demented nursing home patients. Archives of Internal Medicine 1992;152:1885-8

8 Dorff E. Matters of life and death. A fewish approach to modern medical ethics. Philadelphia, PA: Jewish Publication Society, 1998.

9 Rosner F. Jewish perspectives on death and dying. Fewish Medical Ethics 1991;II:38-45.

10 Rosner F. Jewish medical ethics. Fournal of Clinical Ethics 1995; 6:202-17.

11 Schostak Z. Ethical guidelines for treatment of the dying elderly. Fournal of Halacha and Contemporary Society 1991;22: 62-86.

12 Friedman F. The chronic vegetative patient: a Torah perspective. Fournal of Halacha and Contemporary Society 1993;24:88109.

13 Mitchell S, Kiely D, Lipsitz L. The risk factors and impact on survival of feeding tube placement in nursing home residents with severe cognitive impairment. Archives of Internal Medicine 1997; 157:327-32

14 Gillick M. Rethinking the role of tube feeding in patients with advanced dementia. New England fournal of Medicine 2000;342: 206-10.

15 Evans L, Strumpf N. Tying down the elderly. A review of the literature on physical restraints. Fournal of the American Geriatrics Society 1989;37:65-74.

16 Moss R, LaPuma J. The ethics of mechanical restraints. Hastings Center Report 1991;21:22-5.

17 Schostak Z. Jewish ethical guidelines for resuscitation and artificial nutrition and hydration of the dying elderly. Fournal of Medical Ethics 1994;20:93-100.

18 Tendler M. Responsa of Rav Moshe Feinstein: translation and commentary. Volume 1: care of the critically ill. Hoboken, New Jersey: KTAV Publishing House, Inc, 1996.

19 Rosin A, Sonnenblick M. Autonomy and paternalism in geriatric medicine. The Jewish ethical approach to issues of feeding terminally ill fournal of Medical Ethics 1998;24:44-8.

20 McCann R, Hall W, Groth-Juncker A. Comfort care for terminally ill patients. Fournal of the American Medical Association 1994;272:1263-6.

21 Slomka J. What do apple pie and motherhood have to do with feeding tubes and caring for the patient? Archives of Internal Medicine 1995;155:1258-63.

22 Steinbrook R, Lo B. Artificial feeding - solid ground, not a slippery slope. New England Fournal of Medicine 1988;318:286-90. 